Research Article

\title{
Experimental Investigation on Stirring Rate Affecting Bubble Structure of Resin Anchor Agent and Anchoring Strength
}

\author{
Jiaguang Kan, ${ }^{1}$ Yuantian Sun ${ }^{D},{ }^{1}$ Yifan Wang, ${ }^{1}$ Sen Yang, $^{2}$ and Peng Wang ${ }^{1}$ \\ ${ }^{1}$ School of Mines, Key Laboratory of Deep Coal Resources Mining, Ministry of Education, \\ China University of Mining \& Technology, Xuzhou, Jiangsu 221116, China \\ ${ }^{2}$ College of Energy Engineering, Xi'an University of Science and Technology, Xi'an, Shangxi 710054, China
}

Correspondence should be addressed to Yuantian Sun; yuantiansun@cumt.edu.cn

Received 14 September 2020; Revised 23 November 2020; Accepted 7 December 2020; Published 18 December 2020

Academic Editor: Jun Liu

Copyright (C) 2020 Jiaguang Kan et al. This is an open access article distributed under the Creative Commons Attribution License, which permits unrestricted use, distribution, and reproduction in any medium, provided the original work is properly cited.

\begin{abstract}
The function of a resin anchoring agent is to bond the rock of a borehole wall with the body of the anchor so the anchor can play an effective supporting role. The anchoring effect is related to the performance of the resin anchoring agent used and to the stirring rate applied during the anchor installation process. In this report, the stirring rate of the resin anchoring agent is evaluated and discussed in terms of how it affects pore structure and anchoring strength. When the stirring rate is in the range of 400-950 r/min, the uniaxial compressive strength of the resin anchoring agent increases proportionally with the stirring rate, and the compressive strength corresponding to the maximum stirring rate is $15.1 \%$ greater than that corresponding to the minimum stirring rate. Conversely, the pore size of the foam inside the resin anchoring agent is inversely proportional to the stirring rate, and the pore size corresponding to the maximum stirring rate is $15.1 \%$ smaller than that corresponding to the minimum stirring rate. The anchoring strength increases proportionally with the stirring rate when the stirring rate is between 400 and $800 \mathrm{r} / \mathrm{min}$. Specifically, the anchoring strength associated with the maximum stirring rate is $9.2 \%$ greater than the anchoring strength corresponding to the minimum stirring rate. As the stirring time increases from 20 to $60 \mathrm{~s}$, the anchoring force first increases and then decreases, with the optimal stirring time determined to be about $50 \mathrm{~s}$. The results presented herein can be applied to improve anchor installation technology and the anchoring strength of resin anchoring agents.
\end{abstract}

\section{Introduction}

A resin anchoring agent is a type of sticky bonding material comprising unsaturated polyester resin, curing agent, accelerator, and other auxiliary materials in a certain proportion [1-4]. The components of this material are typically divided and packed with polyester film into a cartridge. An effective anchoring agent has excellent mechanical properties, including rapid curing at room temperature, high bonding strength, reliable anchoring strength, and good durability. Resin anchoring agents are widely used in roadway supports, shaft installations, and reinforcements of prestressing anchors in hydropower engineering [5-10].

Based on laboratory tests, theoretical analysis, and numerical simulations, scholars have comprehensively analyzed the anchoring mechanism and elucidated numerous factors that influence the anchoring performance of resin anchoring agents [11-14]. In particular, drilling water, flowing water, and water accumulation in the hole have a significant impact on the resin anchoring agent's performance; the drainage effect can be improved by properly arranging the drainage holes [15-18]. In the case of highpressure water injection sealing, the expansion performance of the resin anchoring agent can be enhanced by adding a polyol polyether agent $[19,20]$. The laboratory pull test is an appropriate method for probing the anchoring agent's performance. The temperature has a significant impact on the anchoring performance of a resin anchoring agent; the anchoring force is the largest at a temperature of $25^{\circ} \mathrm{C}$. In a simulated system, the anchoring force of the resin anchor rod exhibited a significant decreasing trend as the drilling temperature increased $[21,22]$. The shape of the anchor also 
affects its anchoring performance. Specifically, the drawing test results for three different bolt shapes (i.e., left-handed nonlongitudinal steel screw bolt, herringbone rib with longitudinal steel screw bolt, and right-handed full-thread steel bolt) indicated that the transverse rib of the left-handed longitudinal-ribbed steel anchor helps push the resin anchoring agent to the end of the anchor to make the necessary anchor segment. In this case, the resin cartridge is compact and full, which improves the anchoring strength [23, 24]. Finally, it has also been determined that the mixing time and the annular thickness of the anchoring agent influence the anchoring quality [25].

A thorough literature survey revealed that existing studies of resin anchoring agents often lack any evaluation of the effect of different stirring rates on the anchoring agent performance; however, the stirring rate is known to influence the solidified compactness of such materials, thus affecting their anchoring performance. Therefore, herein, we report the influence of stirring rate on the internal pore structure and anchoring strength of resin anchoring agents based on uniaxial compression tests, scanning electron microscopy (SEM), and pull-out tests. The results of this study can be applied to improve the anchoring performance of resin anchoring agents.

\section{Materials and Methods}

2.1. Resin Anchor Agent. A primary goal of this work is to study the effect of stirring rate on the outcome of a uniaxial compressive test, and the resin anchoring agent is the most important material in this test. Currently, saturated polyester resin is the most common resin anchoring agent used in coal mines. The resin anchoring agent used in this work was the type Z2350 medium-speed anchoring agent from a single batch produced by Yihai mine equipment company. The performance standard was MT146.1-2002, which involves a gel time greater than $180 \mathrm{~s}$ and an aging time of $30 \mathrm{~min}$. As shown in Figure 1, the first step was to separate the puddle and curing agent from the type Z2350 anchoring agent cartridge and mix the anchoring agent in the same group uniformly. After repeated experiments, the mass ratio of puddle (black) to curing agent (white) was determined as $1: 0.05$. During the experiments, the samples were maintained in a YH-90B standard constant temperature and humidity maintenance box. The rated supply voltage was $220 \mathrm{~V}$, the consumed power was $2000 \mathrm{~W}$, and the temperature was set to $22^{\circ} \mathrm{C}$, as shown in Figure 2 .

2.2. Electric Hand Drill and Stir Head. To perform experiments with a wide range of stirring rates, a handheld electric drill was used to stir the anchoring agent. The input power of the Mod.6132 electric drill was $820 \mathrm{~W}$, and it provided mixing speeds in the range $0-2600 \mathrm{r} / \mathrm{min}$ with a clamp bit diameter of $1-13 \mathrm{~mm}$. Based on the size ranges of the special mold and handheld electric drill clamping bit, the length of the anchorrod body of the stirring head was customized to $300 \mathrm{~mm}$, the clamping part of the anchor-rod body was a $10 \mathrm{~mm} \times 10 \mathrm{~mm}$ square, and the stirring head's diameter was $30 \mathrm{~mm}$.

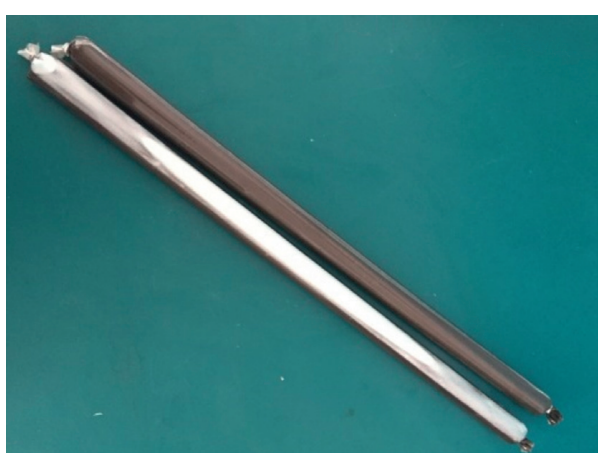

FIGURE 1: Resin anchor agent.

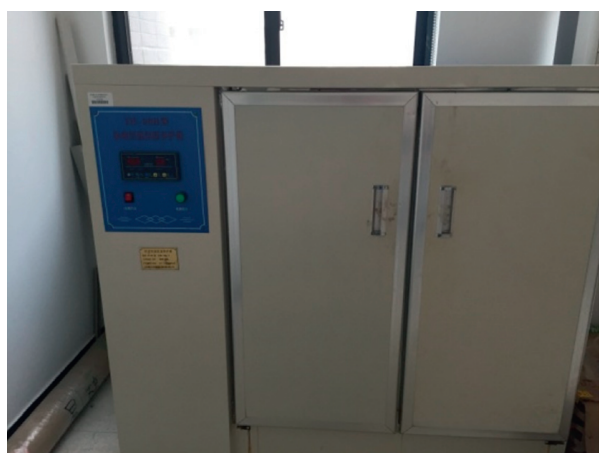

FIGURE 2: Constant temperature and humidity curing box.

To determine the influence of the bolt stirring rate on the hole structure of the resin anchoring agent and the strength of the bolt anchoring force, it is important to control the single variable factor of stirring rate (within a reasonable, designated range) and to eliminate the influence of other factors as much as possible. After repeated experiments and maneuverability and safety considerations, we selected the Z2350 resin anchoring agent and controlled the ambient temperature of the laboratory in the range of $20 \pm 1^{\circ} \mathrm{C}$. According to the underground construction situation and the controllable speed range of the electric drill, the applied stirring rates were $400,600,800$, and $950 \mathrm{r} / \mathrm{min}$. Four sample groups were each subjected to one of these stirring rates, as shown in Table 1.

2.3. Uniaxial Compression Test. The uniaxial compression experiments used a cylindrical mold with an inner diameter of $50 \mathrm{~mm}$ and a height of $100 \mathrm{~mm}$. There were two pairs of four removable screws on each side. To prevent the effects of floating rust on the test outcome, the surface was treated by spraying painting. To prevent adhesion between the anchoring agent test specimen and the inner wall of the mold (which would inhibit smooth removal), a uniform layer was spread over the internal area of the mold and on the bottom of the backing plate needed for the experiment. The screws were then tightened symmetrically on both sides of the mold, which was then fixed onto the backing plate. We calculated the weight of anchoring agent required for each test specimen and weighed the puddle and curing agent 
TABLE 1: Corresponding stirring rate for each group.

\begin{tabular}{lc}
\hline Group number & Stirring rate $(\mathrm{r} / \mathrm{min})$ \\
\hline 1 & 400 \\
2 & 600 \\
3 & 800 \\
4 & 950 \\
\hline
\end{tabular}

according to the ratio of $130 \%-140 \%$. Then, these components were placed together into the stirring vessel for $30 \mathrm{~s}$ to completely mix the puddle and curing agent. This process was repeated for all samples in a group of test specimens, and the speed of the handheld electric drill was adjusted to a different speed to mix the next set of test specimens. As shown in Figure 3, we quickly inverted the anchoring agent with uniform composition into the prepared mold and rolled over the top surface to remove the overflowing anchoring agent. The mold was left to rest during the initial anchoring agent solidification stage.

After $8 \mathrm{~min}$, the mold nut was unscrewed to remove the anchoring agent test specimens, which were numbered and placed into the constant temperature and humidity box. The insulation temperature was set to $22^{\circ} \mathrm{C}$ for $4 \mathrm{~h}$. Overall, 4 groups of 3 samples (12 total resin anchoring agent test specimens) were prepared. After removing a resin anchoring agent test specimen from the incubator, it was left outside for $12 \mathrm{~h}$, and then, the surface was cut and polished to make the two horizontal ends of the specimen smooth, flat, and parallel, as required for the standard uniaxial compressive test. As shown in Figure 4, after processing, the resin anchoring agent cylinders used for the uniaxial compression tests were $40 \mathrm{~mm}$ in diameter and $80 \mathrm{~mm}$ in height. The temperature of the experimental work up was controlled in the range of $20 \pm 1^{\circ} \mathrm{C}$.

The processed resin specimens were placed one-by-one on the CMT5305 electrohydraulic servo universal tester according to their numbers for the uniaxial compression test. Using displacement loading, the speed was set to $1 \mathrm{~mm} /$ $\mathrm{min}$. After each test specimen was tested, the data were saved and the destroyed test piece was removed so the test bed could be cleaned for the next sample. The destroyed condition of a test piece is shown in Figure 5.

2.4. Pull-Out Experiment. Bolt pull-out tests were conducted with a C64.106 static electro-hydraulic servo tester. Hydraulic clamping was applied in the test machine within an adjustable range. The clamping range for this test was $\varphi 15-\varphi 25 \mathrm{~mm}$ and $\varphi 25-\varphi 36 \mathrm{~mm}$, which allowed continuous whole-range measurements. Displacement control was adopted throughout the test, and the speed was set to $5.1 \mathrm{~mm} / \mathrm{min}$.

The construction screw bar with longitudinal anchor reinforcement and a $16 \mathrm{~mm}$ diameter was used as the material for preparing the test anchors. The length of each anchor section was $400 \mathrm{~mm}$, and the length of the anchor section was set to $150 \mathrm{~mm}$. Considering the "three-diameter matching" requirement and the influence of the anchor longitudinal bar on the actual diameter, the drilling of a steel pipe with an inner diameter of $26 \mathrm{~mm}$ and an outer diameter

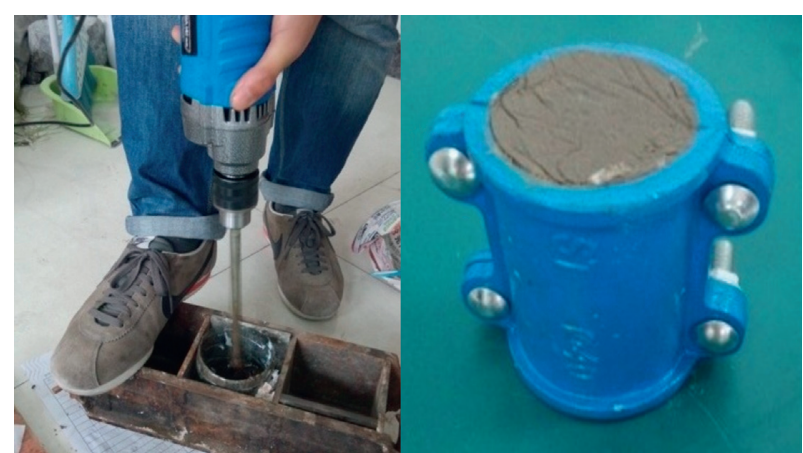

FIgURE 3: Making of resin anchor agent.

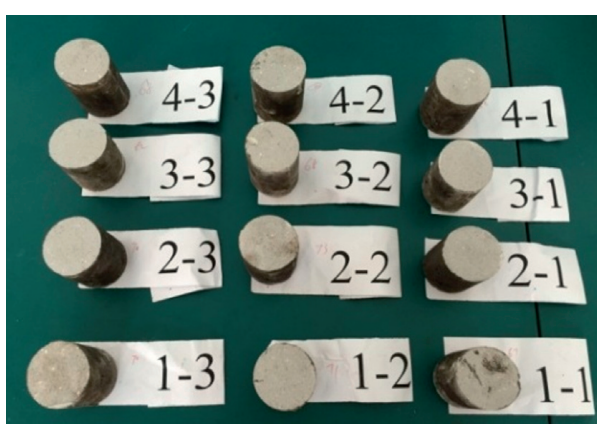

FIGURE 4: Resin anchor agent test specimens.

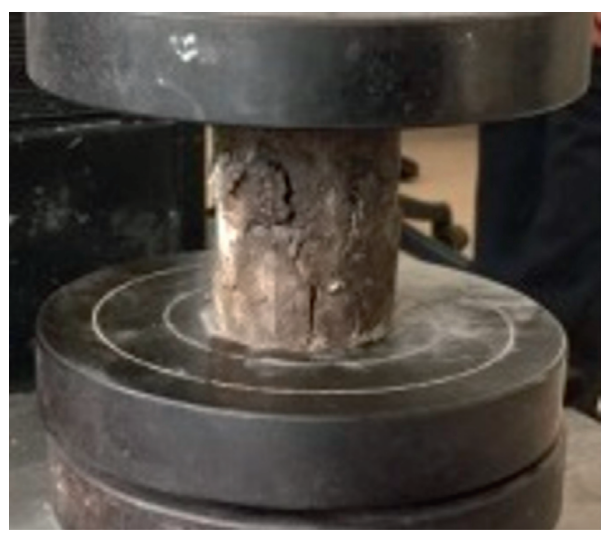

FIGURE 5: Failure schematic diagram of specimens.

of $29 \mathrm{~mm}$ was simulated in this experiment. One end of the 200-mm-long steel pipe was welded to seal the bottom, and the other end was left open. The calculated thickness of the resin anchor ring was $5 \mathrm{~mm}$, and the actual thickness of the anchor ring was about $4 \mathrm{~mm}$, which conforms to the optimal "three-diameter matching" design.

We calculated the weight of anchoring agent required for each pull-out test specimen and weighed the cement and curing agent according to a ratio of about $130 \%-140 \%$. These components were placed in the mixing vessel for $30 \mathrm{~s}$ to fully mix the cement and curing agent. After completing each set of test specimens, the speed of the electric drill was adjusted before testing the next set of specimens. 
The amount of anchoring agent needed for a single pullout specimen was calculated using the following equation:

$$
m=\pi\left(R_{p}^{2} \times L_{b}-R_{b}^{2} \times L_{p}\right) \times \rho,
$$

where $m$ is the mass of anchor agent; $R_{p}$ is the diameter of the steel pipe; $L_{p}$ is the length of the steel pipe; $R_{b}$ is the radius of the anchor; $L_{p}$ is the anchor length; and $\rho$ is the density of anchor agent.

The handheld electric drill was used to stir the cement and curing agent evenly. Then, the anchoring agent was immediately added from the pipe mouth, and the anchor was inserted $150 \mathrm{~mm}$ into the steel pipe anchoring agent; $250 \mathrm{~mm}$ of the anchor remained exposed to ensure that it had been inserted vertically and centrally. The excess anchoring agent at the steel pipe mouth was removed, and we verified that the specimen could stand vertically at the initial solidification stage without touching the anchor in any way. After the anchoring agent solidified in the steel tube, it was placed into the constant temperature and humidity box, and the next group of specimens was prepared. The anchoring agent was taken out after $2 \mathrm{~h}$ (Figure 6).

Displacement loading was used throughout the test, and the speed was set to $5.1 \mathrm{~mm} / \mathrm{min}$. When the residual load of the anchor specimen reached the set parameters, the test was stopped automatically, the tension stress was released, the anchor was removed, and the pull-out test of the next specimen was performed, as shown in Figure 7.

\subsection{Scanning Electron Microscopy (SEM). SEM employs} point-by-point scanning and generates images captured by electron beams focused on the surface of a sample. To date, this method has been widely used for morphological characterizations and in situ process analyses of nonconductive samples, such as inorganic materials, petroleum geological specimens, and biological samples. The macroscopic performance of a resin anchoring agent can be investigated by observing the microscopic morphology of the resin anchoring agent interface using SEM. The scanning electron microscope used in this work was an FEI QuantaTM 250. To ensure the homology of the pre- and post-test data, we recovered and numbered 12 resin anchoring agent test specimens ( 3 samples prepared at each of 4 mixing rates) after the uniaxial compression test and then analyzed these samples using SEM. After collecting the resin anchoring agent test specimens and completing the uniaxial compression test, we identified preferable sections of each test specimen and cut thin slices (thickness $=5 \mathrm{~mm}$ ), which were then segmented to produce thin square samples $(10 \mathrm{~mm} \times 10 \mathrm{~mm} \times 5 \mathrm{~mm})$. Finally, we polished the edges and corners uniformly to make each specimen similar in shape and size, polished one side smoothly, and grouped them according to their numbers from the uniaxial compression test. To obtain high-resolution images, ion sputtering equipment was used to plate gold on the surface of the anchoring agent samples as a conductive film (gold spraying treatment), as shown in Figure 8.

The resin anchoring agent samples were biphasic systems comprising (i) the solid formed by the anchoring agent

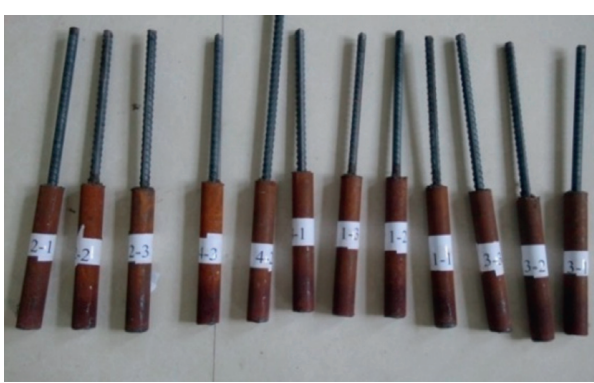

FIgURE 6: Process of making the pull-out specimen.

mixture (solid, continuous phase) and (ii) the gas therein (gaseous, dispersed phase). In the two-dimensional SEM images shown in Figure 9, the bubble cavity area appears as a light grey-white color, the polymer is dark (black), and there is a color transition zone between the bubble cavity and the solid interface. Employing computer-assisted image analysis technology, we were able to identify, distinguish, extract, and calculate the bubble cavity and polymer region areas. This was achieved by moving the observation window, selecting appropriate locations to capture a bubble cavity structural image, and then applying 200, 1000, 2000, or 5000 times magnification to take photographs of each selected point. The SEM images in Figure 9 show 200-5000 times magnification of the same position on the same resin anchor slice. The degree of particle mixing uniformity, the structure of the bubble cavity, the transition zone between the bubble and the solid anchoring agent, and the defects on the surface caused by processing can be observed clearly in the images with different magnifications. As a result, the structure of the material can be described in detail although the artificial defects must be discriminated during image processing.

\section{Results and Discussion}

3.1. Compressive Strength. Uniaxial pressure-displacement curves and results obtained from the compressive tests are presented in Figure 10 and Table 2, respectively.

Each tested stirring rate $(400,600,800$, and $950 \mathrm{r} / \mathrm{min})$ was used to prepare three specimens, leading to 12 datasets from this experiment. The uniaxial compressive strength of each specimen was determined on the basis of the maximum pressure value obtained from the instrument, and the average compressive strength of all test specimens in each group was considered as the ultimate uniaxial compressive strength. However, if the deviation within any sample group was too large (i.e., if the difference between the maximum or minimum value and the median value was more than $10 \%$ ), the median value of the group was taken as the ultimate uniaxial compressive strength.

The relationship between the uniaxial compressive strength and the stirring rate of the test specimens is shown in Figure 11, and the relationship between the average compressive strength and the stirring rate of anchor specimens is shown in Figure 12. The stirring rates of resin anchoring agents ranged from 400 to $950 \mathrm{r} / \mathrm{min}$. Analysis of the uniaxial compressive test results allows for three main conclusions. 


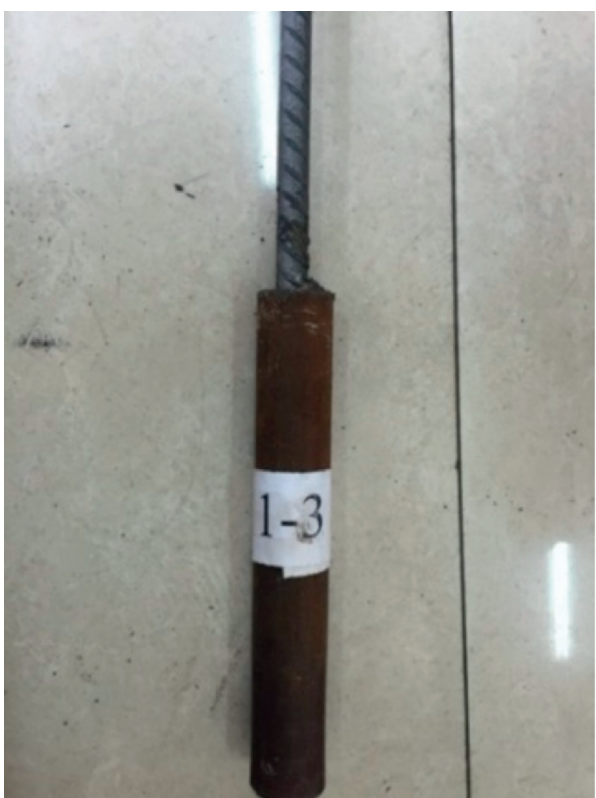

(a)

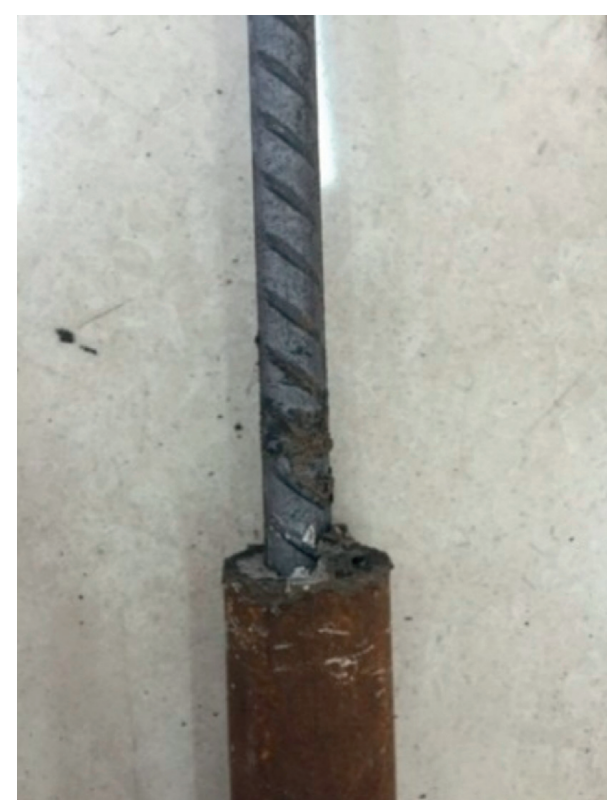

(b)

FIgURE 7: Specimen failure schematic diagram.

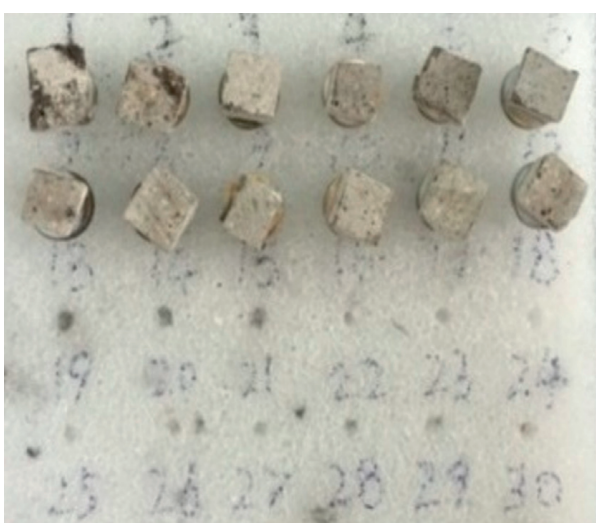

(a)

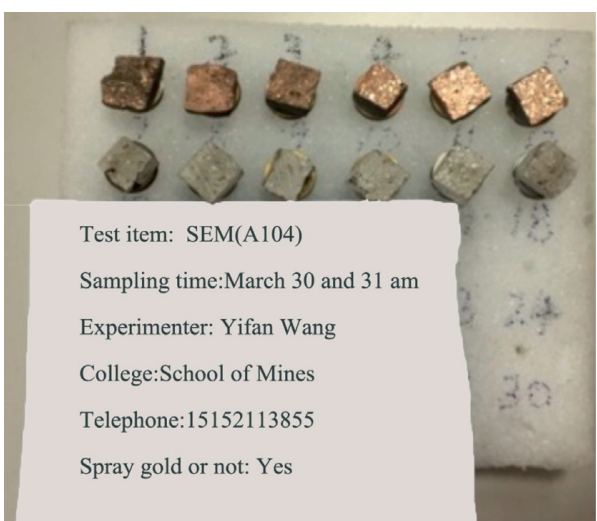

(b)

FIGURE 8: Gold spraying treatment of specimens.

First, the pressure-displacement curves of the 12 resin anchoring agent test specimens at four different stirring rates are concave, smooth, and destructive. When axial pressure is applied, the distance between molecules in the resin anchoring agent specimen decreases. When the pressure begins to increase, the fractures in the specimen expand transversely once the distance between molecules has decreased to a certain extent and then enter the yield stage (i.e., plastic stage). As the pressure is increased further, the fractures in the specimen continue to expand until the sample is destroyed.

Additionally, only the 1-1 specimen was severely fractured when it was damaged. The failure section of other specimens was inclined relative to the axis by about $45^{\circ}-55^{\circ}$, and the surface specimens were destroyed via dislocation along the oblique section.

Finally, based on the results presented in Figures 11 and 12 , it is clear that the uniaxial compressive strength of the anchoring agent specimens is proportional to the stirring rate within the tested range. Specifically, the faster the stirring rate during the anchoring agent installment, the higher its uniaxial compressive strength. In the tested stirring rate range of $400-950 \mathrm{r} / \mathrm{min}$, the uniaxial compressive strength of resin anchoring agent specimens increased by $4.2 \%, 6.0 \%$, and $4.6 \%$ with each incremental increase in stirring rate. The compressive strength corresponding to the maximum stirring rate increased by $15.1 \%$ relative to that corresponding to the minimum stirring rate. 


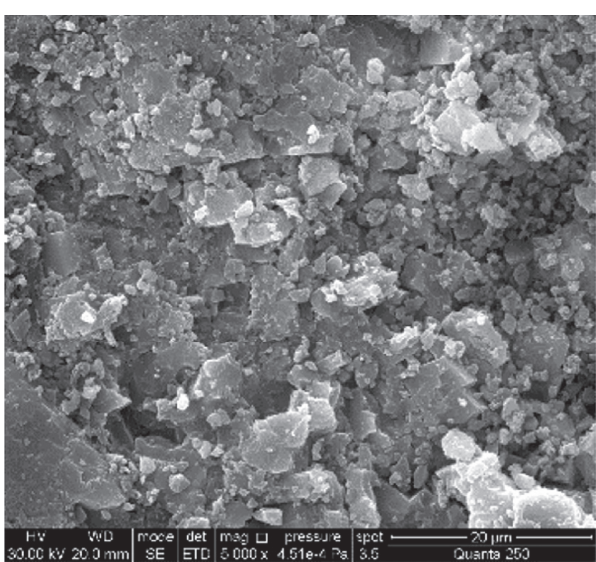

(a)

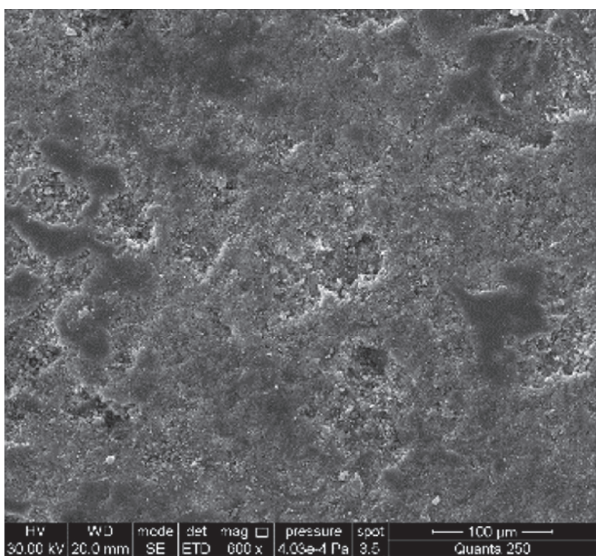

(c)

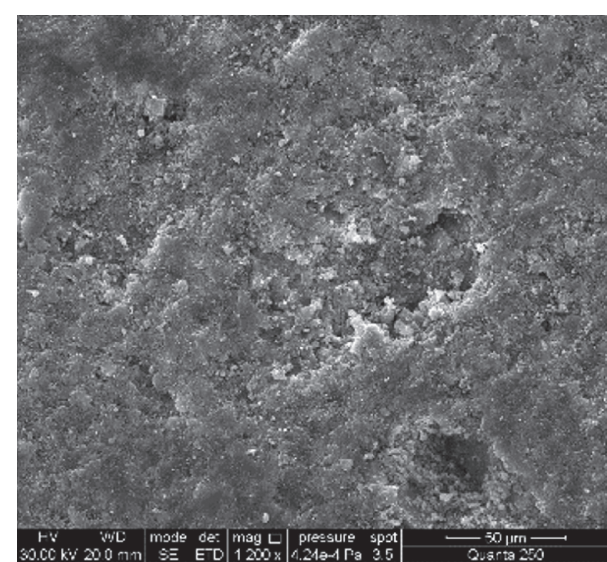

(b)

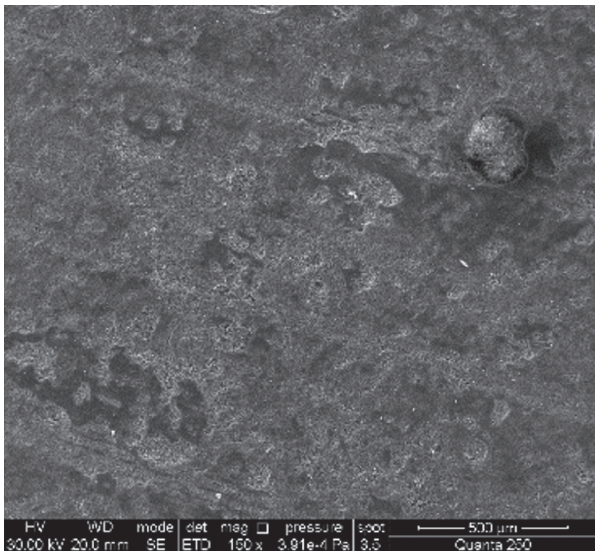

(d)

FIgURE 9: Scanning electron microscope pictures with different multiples.

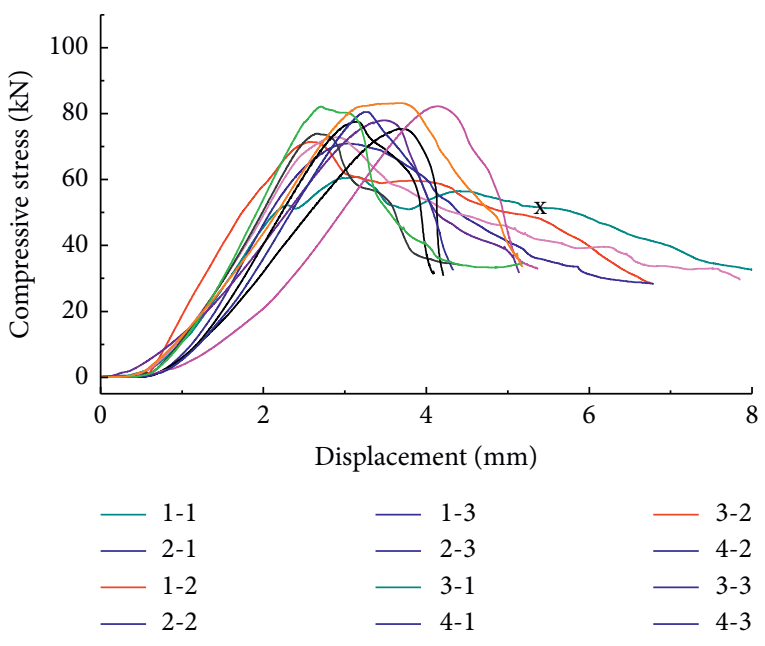

Figure 10: Uniaxial pressure and displacement curve.

Therefore, we concluded that accelerating the stirring rate has a significant positive effect on the uniaxial compressive strength of resin anchoring agent specimens.
3.2. SEM Analysis. SEM allows the calculation of pore apertures and distribution over a certain area. According to the bubble structure disorder hypothesis, when the number of bubble holes is greater than a certain critical value, the relationship between the average bubble area and average pore size on the bubble structure image can be evaluated with a quantitative function. Specifically, the average pore size can be calculated by determining the average bubble area, as shown in Figure 13.

When the number of bubbles approaches infinity, the relationship between the average bubble section area and the average bubble diameter can be determined using the following equation:

$$
\bar{A}=\int_{0}^{R} A \frac{\mathrm{d} x}{R}=\frac{1}{R} \int_{0}^{R} \pi\left(R^{2}-x^{2}\right) \mathrm{d} x=\frac{2}{3} \pi R^{2}=\frac{\pi}{6} d^{2} .
$$

The average bubble diameter can be obtained by an inverse calculation, as shown in the following equation:

$$
d=\left(\frac{\pi}{6}\right)^{1 / 2} \bar{A}^{1 / 2}=1.382 \bar{A}^{1 / 2}
$$


TABle 2: Data of the uniaxial compressive test.

\begin{tabular}{|c|c|c|c|c|c|c|}
\hline Group number & Number & $\begin{array}{l}\text { Stirring rate } \\
(\mathrm{r} / \mathrm{min})\end{array}$ & Maximum stress $(\mathrm{kN})$ & $\begin{array}{c}\text { Average } \\
\text { stress (kN) }\end{array}$ & Uniaxial compressive strength $(\mathrm{MPa})$ & $\begin{array}{c}\text { Mean } \\
\text { strength }(\mathrm{MPa})\end{array}$ \\
\hline \multirow{3}{*}{1} & $1-1$ & \multirow{3}{*}{400} & $60.771 \times$ & \multirow{3}{*}{70.912} & $48.38 \times$ & \multirow{3}{*}{56.46} \\
\hline & $1-2$ & & $71.372 \times$ & & $56.82 \times$ & \\
\hline & $1-3$ & & 70.912 & & 56.46 & \\
\hline \multirow{3}{*}{2} & $2-1$ & \multirow{3}{*}{600} & 71.837 & \multirow{3}{*}{74.235} & 57.19 & \multirow{3}{*}{58.83} \\
\hline & $2-2$ & & 75.951 & & 60.47 & \\
\hline & $2-3$ & & 73.918 & & 58.85 & \\
\hline \multirow{3}{*}{3} & $3-1$ & \multirow{3}{*}{800} & 77.475 & \multirow{3}{*}{78.352} & 61.68 & \multirow{3}{*}{62.38} \\
\hline & $3-2$ & & 76.379 & & 60.81 & \\
\hline & $3-3$ & & 81.203 & & 64.65 & \\
\hline \multirow{3}{*}{4} & $4-1$ & \multirow{3}{*}{950} & 80.513 & \multirow{3}{*}{81.93} & 64.10 & \multirow{3}{*}{65.23} \\
\hline & $4-2$ & & 82.091 & & 65.36 & \\
\hline & $4-3$ & & 83.186 & & 66.23 & \\
\hline
\end{tabular}

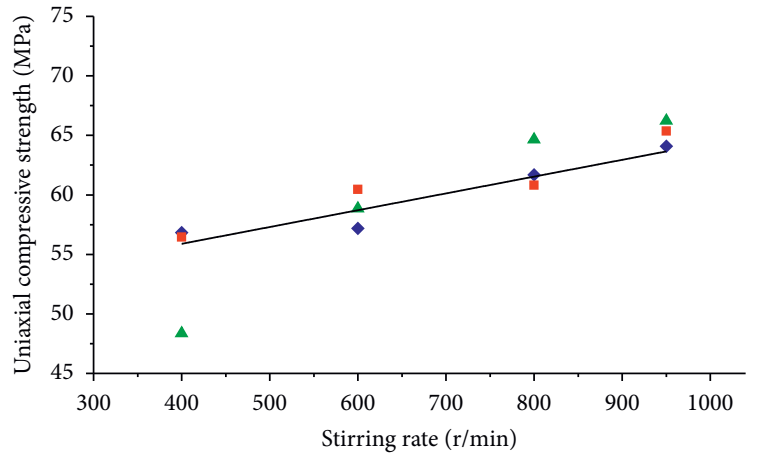

FIgURE 11: Trend curve of compressive strength-stirring rate relation.

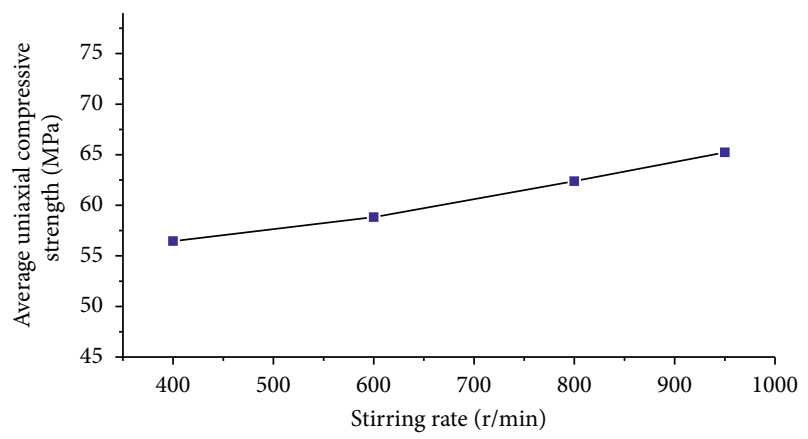

FIGURE 12: Average compressive strength-stirring rate relation.

where $A$ is the area of arbitrary bubble section; $x$ means the distance of arbitrary interface and the centre of bubble; $R$ is the pore size; and $\bar{A}$ is the average area of bubble section.

After screening and comparing all images, the final selected image processing parameters were a scale of 500 microns and magnification of 200 times. For proper image analysis, the following principles should be followed: (i) the defect areas resulting from human activities must be identified and not delineated (three oblique scratch defects caused by specimen cutting are clearly seen in Figure 14); (ii) consistent rules must be followed for describing incomplete bubbles on the image boundary; (iii) there must be a strict

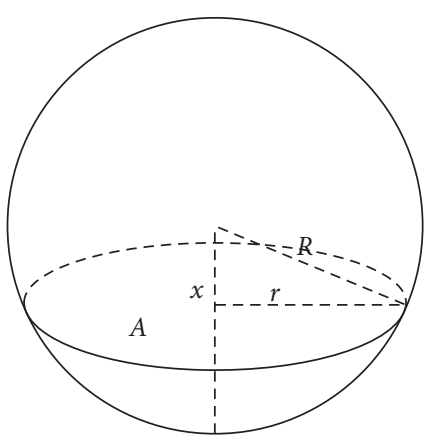

FIGURE 13: Relationship between bubble section and aperture.

guarantee that the described bubbles are in a disconnected state; and (iv) the shape must remain unchanged along the outer edge of the pore structure. Figure 14 illustrates the process of preprocessing the bubble cavity in a section of an anchor slice specimen.

After preprocessing the SEM images, Sigma Scan Pro software was used to measure and extract the data related to the bubble cavity structure in each image. After sorting the output data from the Sigma Scan Pro software, equation (2) was used to determine the quantity and size of pores in each anchor slice specimen, and the data obtained for each anchor slice specimen are shown in Table 3. Additionally, the aperture distribution of each group of specimens is shown in Figure 15, the relationship between the average pore size and the stirring rate is shown in Figure 16, and the relationship between the average compressive strength and the average pore size of each anchor specimen is shown in Figure 17.

The pore size characterization results for the 12 resin anchoring agent specimens are compiled in Table 3. N1 and N2 denote the total number of bubbles at two distinct locations on the surface of the same specimen, $D 1$ and $D 2$ represent the average apertures at two distinct locations on the same specimen, $D$ is the average aperture of two locations on one specimen, and $|D 1-D 2|$ is the difference between the average aperture at two locations on the same specimen. The repeatability and reliability of the results were verified by comparing and analyzing the values of $|D 1-D 2|$ at different locations of the same specimen. Based on the 


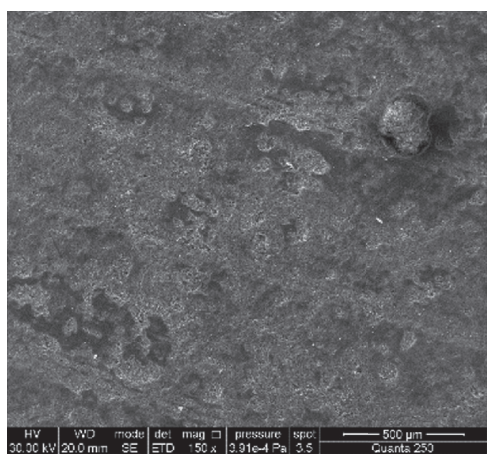

(a)

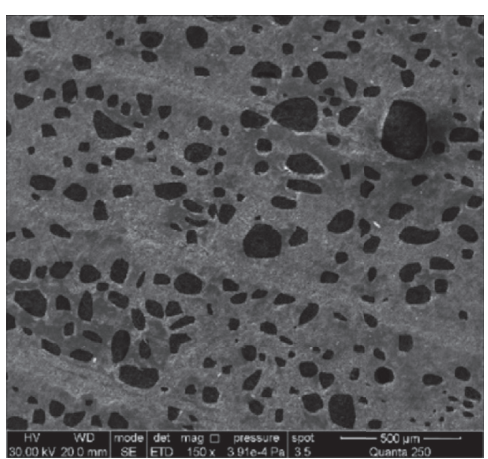

(b)

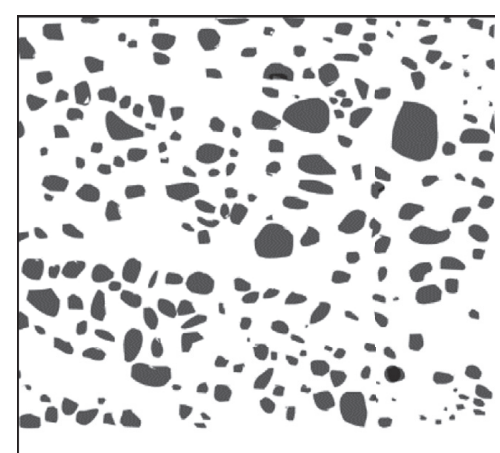

(c)

Figure 14: Preprocessing of sectional face structure.

TABLE 3: Characterization of specimens aperture data.

\begin{tabular}{|c|c|c|c|c|c|c|c|}
\hline Group number & Number & $N_{1} /$ individual & $\mathrm{N}_{2} /$ individual & $D_{1}(\mu \mathrm{m})$ & $D_{2}(\mu \mathrm{m})$ & $\left|D_{1}-D_{2}\right|(\mu \mathrm{m})$ & $D(\mu \mathrm{m})$ \\
\hline \multirow{3}{*}{1} & $1-1$ & 185 & 190 & 70.17 & 65.11 & 5.06 & \multirow{3}{*}{65.08} \\
\hline & $1-2$ & 173 & 194 & 67.03 & 66.56 & 0.47 & \\
\hline & $1-3$ & 218 & 230 & 62.18 & 59.43 & 2.75 & \\
\hline \multirow{3}{*}{2} & $2-1$ & 213 & 189 & 63.98 & 65.62 & 1.64 & \multirow{3}{*}{62.74} \\
\hline & $2-2$ & 209 & 199 & 60.09 & 64.54 & 4.45 & \\
\hline & $2-3$ & 228 & 192 & 59.48 & 64.73 & 5.25 & \\
\hline \multirow{3}{*}{3} & $3-1$ & 227 & 209 & 58.57 & 61.16 & 2.59 & \multirow{3}{*}{57.26} \\
\hline & $3-2$ & 238 & 230 & 56.01 & 58.39 & 2.38 & \\
\hline & $3-3$ & 229 & 244 & 56.23 & 52.42 & 3.81 & \\
\hline \multirow[b]{2}{*}{4} & $4-1$ & 221 & 236 & 56.54 & 53.62 & 2.92 & \multirow{2}{*}{55.31} \\
\hline & $4-2$ & 232 & 227 & 56.32 & 59.39 & 3.07 & \\
\hline
\end{tabular}

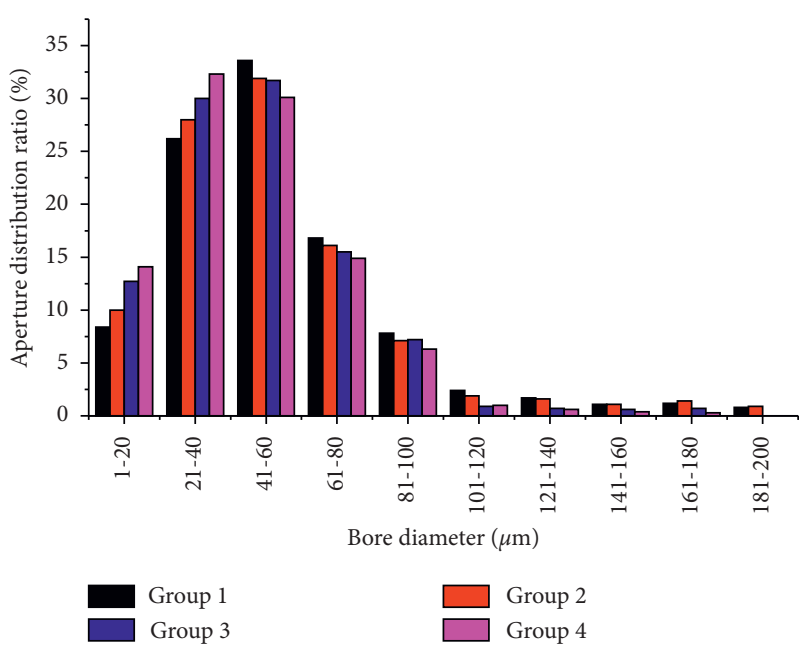

FIgURE 15: Total aperture distribution ratio of each group of specimens.

data in Table 3, the value of $|D 1-D 2|$ decreases as the number of bubbles in the SEM image increases. When the number of bubbles in the SEM image is greater than 200, the maximum error of this method is estimated to be less than $\pm 3.81 \mu \mathrm{m}$, that is, $6.77 \%$. Therefore, the data processed using this method have sufficient repeatability and reliability.

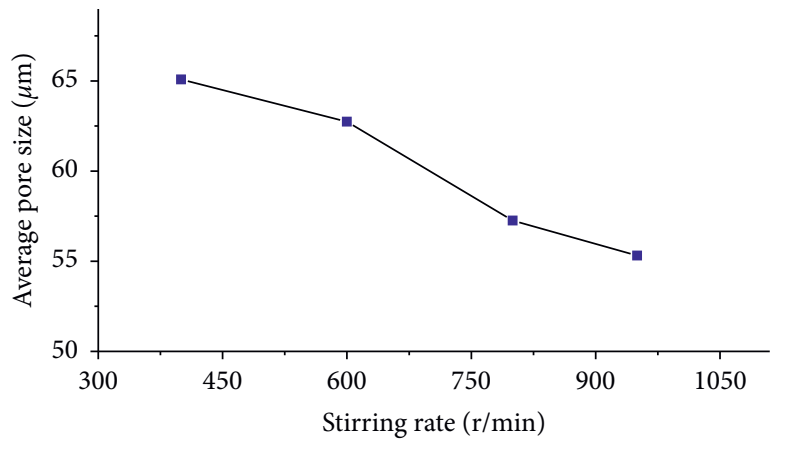

Figure 16: Average aperture and stirring rate relation.

Our calculations revealed that the gas content in the resin anchoring agent specimens was basically the same regardless of the applied stirring rate, indicating that the stirring rate had a limited effect on the gas content (i.e., porosity) of the resin anchoring agent. Therefore, the porosities of the anchoring agent specimens in this study were considered invariant although there were six sets of data for each group of three samples. Based on the obtained results, there were some slight errors, but the data still reflect the distribution of bubble cavity size because it relates to the corresponding stirring rate. Additionally, according to Figure 15, the pore size distribution in each group of specimens under different stirring rates essentially follows a 


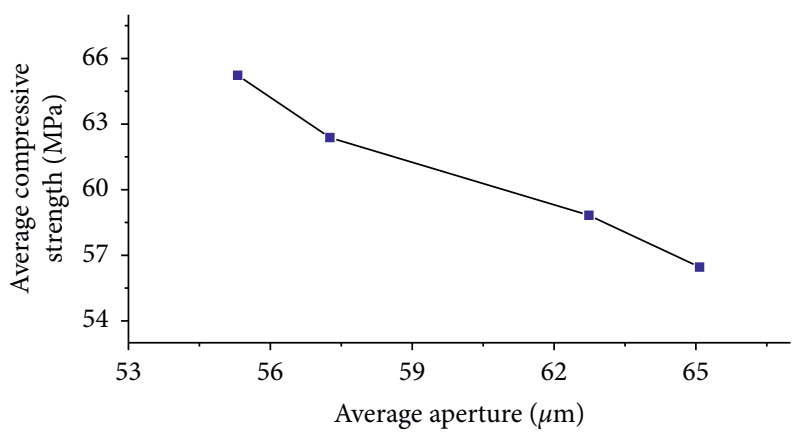

FIgURE 17: Average compressive strength and average aperture relation.

normal distribution, and the pore size is mainly concentrated in the range of $20-60 \mu \mathrm{m}$. As the stirring rate increases, the proportion of small pores increases and the proportion of large pores decreases. Figure 17 shows that the uniaxial compressive strength of the resin anchoring agents is inversely proportional to the size of internal pores in the tested range of stirring rates. Specifically, the smaller the pore size, the greater the strength, and the larger the pore size, the weaker the resin anchoring agent. Finally, based on Figure 16, it is clear that the internal bubble pore size in the resin anchoring agent specimen is inversely proportional to the stirring rate within the tested range. Specifically, the faster the stirring rate, the smaller the pores in the resin anchoring agent. Within the stirring rate range of 400-950 r/ $\mathrm{min}$, the average pore size of bubbles in the resin anchoring agent specimens decreases by $3.60 \%, 8.78 \%$, and $3.41 \%$ with each increasing stirring rate interval; the average pore size at the maximum stirring rate is $15.1 \%$ smaller than that at the slowest stirring rate. The pore size of bubbles in the solid samples has a significant effect on the material's performance.

3.3. Anchoring Force of Bolt. As stated previously, the average value of the maximum anchoring strength of each group of specimens was considered as that group's final anchoring strength, and if the data deviation within any group of specimens was too large (i.e., if the difference between the maximum or minimum value and the median value was more than $10 \%$ ), the median value was considered as the group's final anchoring strength. The results obtained from the bolt anchoring force tests are shown in Table 4.

The relationship between the anchor-hold force and the stirring rate is shown in Figure 18, and the relationship between the anchoring strength and the stirring rate is shown in Figure 19. Because of the conditions for these tests, the stirring rate range for all resin anchoring agents was between 400 and $800 \mathrm{r} / \mathrm{min}$ (i.e., stirring rates of 400,600 , and $800 \mathrm{r} / \mathrm{min}$ were tested). Although there are no clear differences among the nine datasets, the combined results presented in Table 4 and Figure 18 show an increasing proportional trend. After excluding the failure data, it is clear that the anchoring strength of the resin anchors increases with increasing stirring rates. The relationship between the average anchoring strength and the stirring rate indicates that the anchoring strength of a resin-anchored bolt is proportional to the stirring rate within a certain range. Specifically, the faster the stirring rate, the greater the anchoring strength of the resulting resin-anchored bolt. In the stirring rate range of $400-800 \mathrm{r} / \mathrm{min}$, the anchoring strength of resin anchoring agents increased by $4.0 \%$ and $5.0 \%$ with each increasing interval in the stirring rate. The anchoring strength corresponding to the maximum stirring rate increased by $9.2 \%$ compared with that corresponding to the minimum stirring rate. These results allowed us to conclude that increasing the stirring rate has a remarkable effect on the anchoring strength of resin anchoring agents.

Using an appropriate stirring rate renders the anchoring agent mixture more uniform and improves its anchoring strength and performance. However, during the on-site construction process, different stirring durations may also affect the performance of the anchoring agent. Therefore, bolt pull-out tests were performed to evaluate the influence of the mixing time on the strength of the resin anchoring agent. The experimental materials are the same as those used for the tests described above. To retain the underground bolt construction as much as possible and to reduce the interference of human factors during the mixing process, the cement was not separated from the curing agent in this test, but rather, the anchoring agent cartridge contents were placed into the steel pipe as a whole. The MZ-II anchor-cable installation device was used to complete the anchor rod installation, as shown in Figure 20, and then, the excess section of the rod body was cut. The normal stirring rate of this instrument is $190 \mathrm{r} / \mathrm{min}$; a total of five sets of three anchor rod anchoring specimens were produced, and the corresponding stirring time for each set was $20,30,40,50$, or $60 \mathrm{~s}$.

The average value of the maximum anchoring strength of each group of specimens was taken as the final group anchoring strength. The data obtained from this test are shown in Table 5 .

The relationship between the average anchoring strength of each group and the stirring time is shown in Figure 20.

This figure shows the pull-out failure and average anchoring force curve of the resin anchoring agent after different stirring times. The average anchoring force of each group of anchor rods is $33.963 \mathrm{kN}(20 \mathrm{~s}), 47.001 \mathrm{kN}(30 \mathrm{~s})$, $47.417 \mathrm{kN}(40 \mathrm{~s}), 69.475 \mathrm{kN}(50 \mathrm{~s})$, and $52.358 \mathrm{kN}(60 \mathrm{~s})$. These results confirm that the pull-out force for an anchor rod depends on the stirring time. In general, the pull-out force increases with increasing stirring time in the range of 
TABle 4: Pull-out experiment data.

\begin{tabular}{|c|c|c|c|c|}
\hline Group number & Number & Agitation rate (r/min) & Maximum anchoring strength $(\mathrm{kN})$ & Average anchoring strength $(\mathrm{kN})$ \\
\hline \multirow{3}{*}{1} & $1-1$ & & 74.76 & \multirow{3}{*}{76.37} \\
\hline & $1-2$ & 400 & 75.61 & \\
\hline & $1-3$ & & 78.74 & \\
\hline \multirow{3}{*}{2} & $2-1$ & & 78.33 & \multirow{3}{*}{79.41} \\
\hline & $2-2$ & 600 & 77.84 & \\
\hline & $2-3$ & & 82.06 & \\
\hline \multirow{3}{*}{3} & $3-1$ & & 83.36 & \multirow{3}{*}{83.36} \\
\hline & $3-2$ & 800 & $73.98 \times$ & \\
\hline & $3-3$ & & $85.21 \times$ & \\
\hline
\end{tabular}

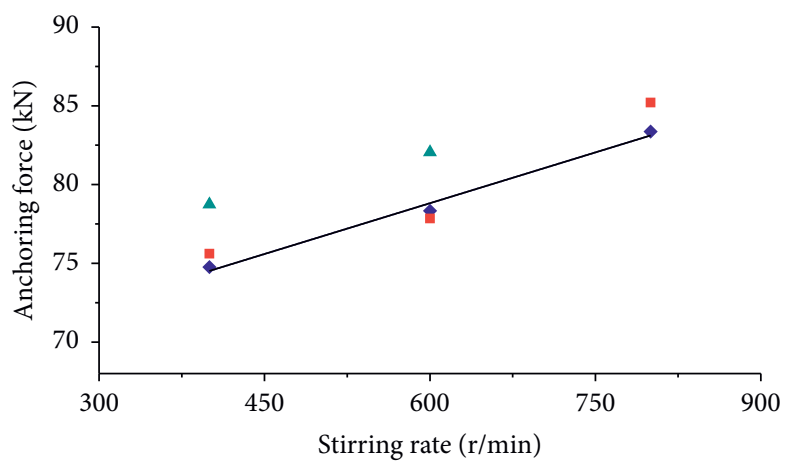

FIgURE 18: Anchor stress-stirring rate trend.

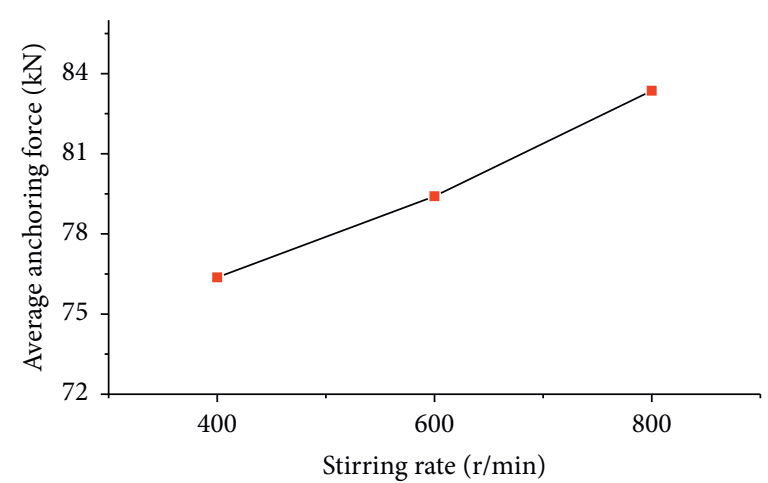

FIGURE 19: Average anchor stress-stirring rate relationship.

20-50 s. However, when the stirring time exceeds $50 \mathrm{~s}$, the pull-out force of the anchor rod decreases. Additionally, based on the relationship between the average anchoring force and the stirring time, it is clear that the anchoring force increases by about 2.05 times as the stirring time increases from 20 to $50 \mathrm{~s}$. This is because with a short stirring time of $20 \mathrm{~s}$, there is insufficient mixing of the cement and the curing agent, which results in a limited degree of bonding between the anchoring agent rod body and anchoring agent pipe wall, which leads to a low anchoring strength. With a longer stirring time, the cement and curing agent are allowed to mix completely, and there is more anchoring interface contact and adhesion, so the anchoring strength increases significantly. However, when the stirring time is too long ( $>50 \mathrm{~s}$ ), the structure of the fully-stirred cement/curing agent mixture is destroyed before it solidifies. In addition, at longer mixing times, there is a risk that the anchoring agent was ejected because of centrifugal force, thus resulting in the separation of the two-phase anchoring system, which leads to a reduced anchoring force. Based on these results, the optimal mixing time for resin-anchored bolt construction is about $50 \mathrm{~s}$. In the field construction process, increasing the mixing time while ensuring efficiency can improve the anchoring effect of resin-anchored bolts. 


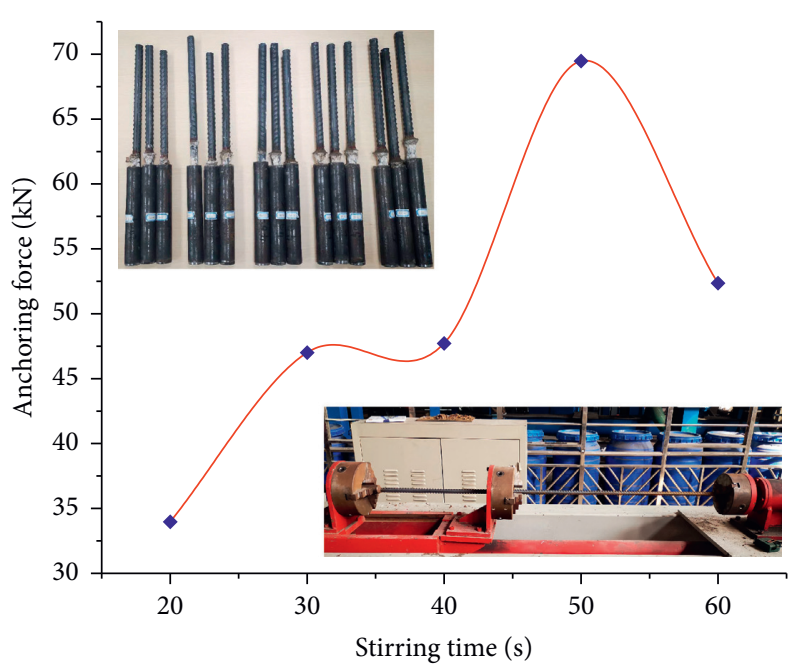

FIgURE 20: Average anchor stress-stirring time relationship.

TABle 5: Anchor force at different stirring time.

\begin{tabular}{|c|c|c|c|c|}
\hline Group number & Number & Stirring time $(\mathrm{s})$ & Maximum anchoring strength $(\mathrm{kN})$ & Average anchoring strength $(\mathrm{kN})$ \\
\hline \multirow{3}{*}{1} & $20-1$ & & 25.469 & \multirow{3}{*}{33.963} \\
\hline & $20-2$ & 20 & 44.655 & \\
\hline & $20-3$ & & 31.765 & \\
\hline \multirow{3}{*}{2} & $30-1$ & & 56.883 & \multirow{3}{*}{47.001} \\
\hline & $30-2$ & 30 & 32.509 & \\
\hline & $30-3$ & & 51.612 & \\
\hline \multirow{3}{*}{3} & $40-1$ & & 48.188 & \multirow{3}{*}{47.417} \\
\hline & $40-1$ & 40 & 43.402 & \\
\hline & $40-1$ & & 50.661 & \\
\hline \multirow{3}{*}{4} & $50-1$ & & 87.984 & \multirow{3}{*}{69.475} \\
\hline & $50-1$ & 50 & 49.894 & \\
\hline & $50-1$ & & 70.549 & \\
\hline \multirow{3}{*}{5} & $60-1$ & & 70.901 & \multirow{3}{*}{52.358} \\
\hline & $60-1$ & 60 & 41.122 & \\
\hline & $60-1$ & & 45.052 & \\
\hline
\end{tabular}

\section{Conclusions}

In this report, the effects of stirring rate on the mechanical properties of resin materials and the morphology of the generated bubbles and pores are discussed. We present a method to improve the pore structure and anchoring strength of resin anchoring agents by changing the stirring rate and duration. This work is supported by comprehensive theoretical analysis, laboratory testing, and verified simulation tests. The relationship between the mechanical properties of the resin anchoring agent and the internal pore structure of the bubbles was analyzed thoroughly, and the pull-out test of anchoring strength with an anchor rod was conducted. The main conclusions from the experiments and analysis are as follows:

(1) The uniaxial compressive strength of the resin anchoring agent increases proportionally to the stirring rate in the range of $400-950 \mathrm{r} / \mathrm{min}$. The uniaxial compressive strength corresponding to the maximum stirring rate increased by approximately $15.1 \%$ compared with that corresponding to the minimum stirring rate.

(2) The pore size of the resin anchoring agent in the foam is inversely proportional to the stirring rate in the range of $400-950 \mathrm{r} / \mathrm{min}$. The pore size corresponding to the maximum stirring rate decreased by $15.01 \%$ compared with that corresponding to the minimum stirring rate.

(3) Porosity and pore size are important factors affecting the anchoring strength of a resin material; in general, the anchoring strength decreases with increasing porosity and pore size. If the porosity remains unchanged, the strength of the resin anchoring agent is inversely proportional to the pore size of internal bubbles. This indicates that the larger the pore size of bubbles in a resin anchoring agent specimen, the lower the strength of that anchoring agent. Increasing the stirring rate can significantly decrease the pore size of large and small holes in the anchoring agent. 
(4) The anchoring strength is proportional to the stirring rate, and it increases and then decreases with longer stirring times. In the stirring rate range of 400-800 r/ $\mathrm{min}$, the anchoring strength of the material increases with increasing stirring rate. The anchoring strength corresponding to the maximum stirring rate increased by $9.2 \%$ compared with that corresponding to the minimum stirring rate. Additionally, the anchoring force increased by about 2.05 times while increasing the stirring time in the range of $20-50 \mathrm{~s}$; the optimal mixing time for resin anchor bolt construction was determined to be about $50 \mathrm{~s}$.

(5) The optimal stirring rate for underground construction can be determined by adjusting the stirring rate of anchor resin and evaluating the resulting strength. Such understanding reduces the construction workers' labor efforts and improves construction accuracy while enhancing the strength of the anchoring agent. Therefore, the results presented herein can help improve (i) the supporting effect of underground anchor bolts, (ii) the safety of roadway supports, and (iii) the cost-effectiveness of implementing such anchors.

\section{Data Availability}

The Microsoft Excel Worksheet data used to support the findings of this study are available from the corresponding author (yuantiansun@cumt.edu.cn) upon request.

\section{Conflicts of Interest}

The authors declare that they have no conflicts of interest.

\section{Acknowledgments}

This work was supported by the National Key R\&D Program of China (2017YFC0603001), Fundamental Research Funds for the Central Universities (2020ZDPY0221), and the National Natural Science Foundation of China Support (51704276).

\section{References}

[1] Ministry of Coal Industry of the People's Republic of China, Industry Standard of Anchorage Agent for Bolts (MT 146.12011), Ministry of Coal Industry of the People's Republic of China, China, 2011.

[2] X.-B. Li, Z.-L. Zhou, Q.-Y. Li, and L.-Q. Hu, "Parameter analysis of anchor bolt support for large-span and jointed rock mass," Journal of Central South University of Technology, vol. 12, no. 4, pp. 483-487, 2005.

[3] Y. Sun, J. Zhang, G. Li, Y. Wang, J. Sun, and C. Jiang, "Optimized neural network using beetle antennae search for predicting the unconfined compressive strength of jet grouting coalcretes," International Journal for Numerical and Analytical Methods in Geomechanics, vol. 43, no. 4, pp. 801-813, 2019.

[4] J. Fang and W. L. Xu, "The application and study of polyurethane resin," Journal of Wuhan University of Science and Engineering, vol. 16, no. 6, pp. 58-63, 2003.
[5] Y. Sun, J. Zhang, G. Li et al., "Determination of Young's modulus of jet grouted coalcretes using an intelligent model," Engineering Geology, vol. 252, pp. 43-53, 2019.

[6] H. Hojo, K. Ogasawara, W. L. Chang, and K. Tsuda, "Degradation behavior of unsaturated polyester resin in alcohols," Advanced Composite Materials, vol. 3, no. 4, pp. 341-353, 1994.

[7] Z. K. Brzozowski, E. Szymańska, and M. M. Bratychak, "New epoxy-unsaturated polyester resin copolymers," Reactive and Functional Polymers, vol. 33, no. 2-3, pp. 217-224, 1997.

[8] Y. T. Sun, G. C. Li, H. Basarir, A. Karrech, and M. R. Azadl, "Laboratory evaluation of shear strength properties for cement-based grouted coal mass," Arabian Journal of Geosciences, vol. 12, no. 22, 2019.

[9] H. Basarir, Y. Sun, and G. Li, "Gateway stability analysis by global-local modeling approach," International Journal of Rock Mechanics and Mining Sciences, vol. 113, pp. 31-40, 2019.

[10] Y. D. Xue and H. W. Huang, "Perimental study on effect of water on anchoring performance of resin cable bolts," Rock and Soil Mechanics, vol. S1, pp. 31-34, 2005.

[11] Y. Y. Yuan, "Research on matrix failure and mechanical performance of the ceramic matrix composites with pores," Master thesis, Nanjing University of Aeronautics and Astronautics, Nanjing, China, 2008.

[12] Y. Sun, G. Li, N. Zhang, Q. Chang, J. Xu, and J. Zhang, "Development of ensemble learning models to evaluate the strength of coal-grout materials," International Journal of Mining Science and Technology, 2020.

[13] Z. Budai, Z. Sulyok, and V. Vargha, "Glass-fibre reinforced composite materials based on unsaturated polyester resins," Journal of Thermal Analysis and Calorimetry, vol. 109, no. 3, pp. 1533-1544, 2012.

[14] R. Kumar and B. Jee, "Porosity pore size distribution and in situ strengh of concrete," Cement and Concrete Research, vol. 33, no. 1, pp. 155-164, 2003.

[15] W. Pabst and E. Gregorová, "New relation for the porosity dependence of the effective tensile modulus of brittle materials," Journal of Materials Science, vol. 39, no. 10, pp. 3501-3503, 2004.

[16] Y. T. Sun, G. C. Li, J. F. Zhang, and D. Y. Qian, "Experimental and numerical investigation on a novel support system for controlling roadway deformation in underground coal mines," Energy Science \& Engineering, vol. 8, no. 2, pp. 490-500, 2020.

[17] P. F. Gou, Q. X. Chen, and S. Zhang, "Influence analysis of the anchor-hold of the resin bolt by the draining water in the drill hole," Journal of china Coal Society, vol. 6, pp. 680-683, 2004.

[18] G. Y. Song, S. Zhang, and P. F. Gou, "Study on the influence of water on the anchor-hold of resin anchor," Mining and Metallurgical Engineering, vol. 5, pp. 16-19, 2005.

[19] K. Z. Dong, “"Improvement of resin coagulant"s capability and experimentation in the application of sealing holes," Journal of Liaoning Technical University (Natural Science), vol. 3, pp. 321-324, 2008.

[20] B. Hu, H. P. Kang, J. Lin, J. F. Cai, and P. F. Jiang, "Study on influence of temperature on anchorage performance of resin anchored bolt," Journal of Mining \& Safety Engineering, vol. 5, pp. 644-649, 2012.

[21] Y. T. Sun, G. C. Li, J. F. Zhang, and D. Y. Qian, "Stability control for the rheological roadway by a novel high-efficiency jet grouting technique in deep underground coal mines," Sustainability, vol. 11, no. 22, 2019. 
[22] B. Hu, L. Lin, and P. F. Jiang, "Influence of ring thickness of anchored agent on anchored quality of resin anchored bolt," Coal Mining Technology, vol. 4, pp. 20-22, 2011.

[23] H. P. Kang, Q. L. Cui, B. Hu, and Z. G. Wu, "Analysis on anchorage performances and affecting factors of resin bolts," Journal of China Coal Society, vol. 1, pp. 1-10, 2014.

[24] Y. Sun, G. Li, and J. Zhang, "Investigation on jet grouting support strategy for controlling time-dependent deformation in the roadway," Energy Science \& Engineering, vol. 8, no. 6, pp. $2151-2158,2020$.

[25] Z. Y. Wang, "Study on anchoring quality and rebar deformation characteristics of resin bolts," Master thesis, General Institute of Coal Science, Beijing, China, 2014. 